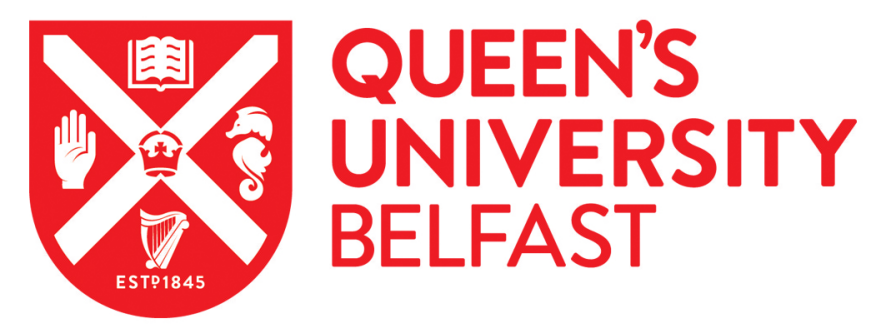

\title{
An infection-responsive approach to reduce bacterial adhesion in urinary biomaterials
}

\author{
McCoy, C. P., Irwin, N. J., Brady, C., Jones, D. S., Carson, L., Andrews, G. P., \& Gorman, S. P. (2016). An \\ infection-responsive approach to reduce bacterial adhesion in urinary biomaterials. Molecular Pharmaceutics, \\ 13(8), 2817-2822. https://doi.org/10.1021/acs.molpharmaceut.6b00402
}

\section{Published in:}

Molecular Pharmaceutics

\section{Document Version:}

Peer reviewed version

Queen's University Belfast - Research Portal:

Link to publication record in Queen's University Belfast Research Portal

\section{Publisher rights}

Copyright 2016 America Chemical Society.

This document is the Accepted Manuscript version of a Published Work that appeared in final form in Molecular Pharmaceutics, after peer review and technical editing by the publisher. To access the final edited and published work, see DOI: 10.1021/acs.molpharmaceut.6b00402

\section{General rights}

Copyright for the publications made accessible via the Queen's University Belfast Research Portal is retained by the author(s) and / or other copyright owners and it is a condition of accessing these publications that users recognise and abide by the legal requirements associated with these rights.

Take down policy

The Research Portal is Queen's institutional repository that provides access to Queen's research output. Every effort has been made to ensure that content in the Research Portal does not infringe any person's rights, or applicable UK laws. If you discover content in the Research Portal that you believe breaches copyright or violates any law, please contact openaccess@qub.ac.uk. 


\title{
An Infection-Responsive Approach to Reduce Bacterial Adhesion in Urinary Biomaterials
}

Colin P. McCoy*, Nicola J. Irwin, Christopher Brady, David S. Jones, Louise Carson, Gavin P. Andrews, Sean P. Gorman

School of Pharmacy, Queen’s University Belfast, 97 Lisburn Road, Belfast BT9 7BL, Northern Ireland, UK.

*To whom correspondence should be addressed. (Tel: +44 289097 2081; Fax: +44 28 9024 7794; e-mail: c.mccoy@qub.ac.uk)

\begin{abstract}
Infection is an inevitable consequence of chronic urinary catheterisation, with associated problems of recurrent catheter encrustation and blockage experienced by approximately $50 \%$ of all long-term catheterised patients. In this work we have exploited, for the first time, the reported pathogen-induced elevation of urine $\mathrm{pH}$ as a trigger for 'intelligent' antimicrobial release from novel hydrogel drug delivery systems of 2-hydroxyethyl methacrylate and vinyl-functionalised nalidixic acid derivatives, developed as candidate infection-resistant urinary catheter coatings. Demonstrating up to 20 -fold faster rates of drug release at $\mathrm{pH} 10$, representing infected urine $\mathrm{pH}$, than at $\mathrm{pH} 7$, and achieving reductions of up to $96.5 \%$ in in vitro bacterial adherence, our paradigm of $\mathrm{pH}$-responsive drug delivery, which requires no external manipulation, therefore represents a promising development towards the prevention of catheter-associated urinary tract infections (CAUTIs) in vivo.
\end{abstract}

\section{Table of Contents Graphic}

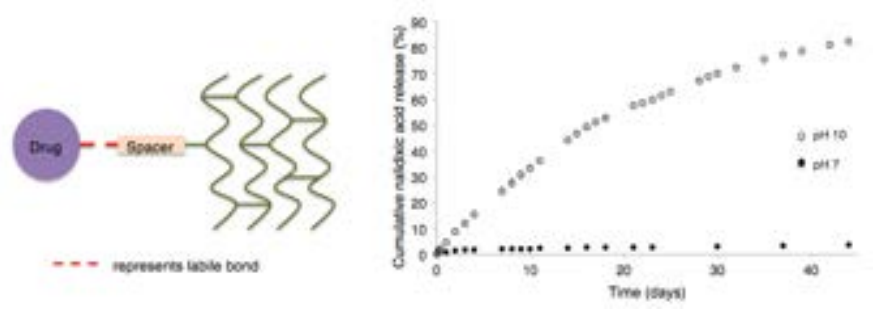

\section{Keywords}

pH-Responsive; Urinary catheter infection; Ester hydrolysis; Drug conjugate copolymer 


\section{Introduction}

The employment of biomaterials in diverse diagnostic and therapeutic applications has led to significant advances within the practice of modern medicine, (1) however, clinical applicability is ultimately limited by their inherent susceptibility to bacterial colonisation. As one of the most predominant biomaterial-associated infections, catheter-associated urinary tract infections (CAUTIs) deserve particular attention. (2) Complications primarily result from activity of the bacterial enzyme, urease, which is secreted by many urinary pathogens, of which Proteus mirabilis is the most notorious. The resulting urease-catalysed hydrolysis of urea into ammonia elevates urinary $\mathrm{pH}$ to reported values up to $\mathrm{pH}$ 9.1, thereby triggering precipitation of magnesium and ammonium phosphate crystals. (3) Complications, including crystalline biofilm formation, catheter encrustation and blockage, are experienced on a recurrent basis by approximately $50 \%$ of all long-term catheterised patients. (4)

Complete eradication of biomaterial-associated infections is difficult due to the recalcitrance of bacteria in the biofilm-mode of growth, therefore much emphasis has now been placed on preventing infections by modification of the device to resist bacterial attachment. Strategies investigated to-date include functionalisation of the surface with bacteria-repelling polymer brushes, (5) use of bioinert multilayer polymer coatings (6) and loading the device with antibacterial agents. Passive, diffusion-controlled release of drug from the matrix interior of currently marketed antimicrobial biomaterials represents a suboptimal release strategy. The antimicrobial lifetime of the device is restricted by an initial burst of surface-localised agent, which is thereafter followed by continuous drug elution in subtherapeutic levels, potentially promoting the emergence of bacterial resistance. (7) One strategy to control release kinetics and ultimately achieve tailored drug delivery with a precise 'on-off' response, (8) while also mitigating the compromise in mechanical properties associated with particulate release from the matrix interior, (9) involves the application of labile drug conjugates to three-dimensional drug delivery systems. $(10,11)$

We have recently described the synthesis and $\mathrm{pH}$-responsive release kinetics of a suite of novel, polymerisable drug conjugates containing the quinolone antimicrobial agent, nalidixic acid, covalently conjugated via hydrolytically labile ester bonds to alkenyl spacer moieties of varying vinyl chain lengths. (12) Of particular significance towards the development of $\mathrm{pH}$-responsive, infection-resistant urinary biomaterials is the faster hydrolysis and subsequent release of nalidixic acid from these conjugates at rates up to 17-fold greater at pH 9.29 than at $\mathrm{pH} 7$. These ester derivatives of nalidixic acid were herein copolymerised, for the first time, with 2-hydroxyethyl methacrylate (2-HEMA), employing ethyleneglycol-dimethacrylate (EGDMA) as a crosslinker, to develop three-dimensional chemically-triggered drug delivery systems. Characterisation of the synthesised copolymers in terms of water wettability, swelling characteristics, $\mathrm{pH}$-mediated release kinetics, and resistance to adherence of P. mirabilis and Staphylococcus aureus informs the use of these drug conjugate-HEMA copolymers as infection-resistant catheter coatings capable of exploiting the elevation of urine $\mathrm{pH}$ reported at the onset of CAUTIs by ureaseproducing urinary pathogens to trigger release of the conjugated antimicrobial agent, specifically through controlled ester hydrolysis. 


\section{Experimental Section}

\section{Materials}

Polymerisable ester nalidixic acid conjugates: 1-ethyl-7-methyl-4-oxo-1,4-dihydro1,8-naphthyridine-3-carboxylic acid 2-propen-1-ol ester 1, 1-ethyl-7-methyl-4-oxo1,4-dihydro-1,8-naphthyridine-3-carboxylic acid 3-buten-1-ol ester 2, and 1-ethyl-7methyl-4-oxo-1,4-dihydro-1,8-naphthyridine-3-carboxylic acid 9-decen-1-ol ester 3, the molecular structures of which are displayed in Figure 1, were synthesised as previously described. (12)

2-Hydroxyethyl methacrylate (2-HEMA), ethyleneglycol-dimethacrylate (EGDMA), phosphoric acid, acetic acid, boric acid, hydrochloric acid, potassium chloride and sodium hydroxide were purchased from Sigma-Aldrich (Poole, Dorset, UK). 2,2'-Azobisisobutyronitrile (AIBN) was obtained from VWR International Ltd. (Lutterworth, UK). Phosphate-buffered saline (PBS), tryptone soya broth (TSB), quarter-strength Ringer's solution (QSRS) and Mueller-Hinton broth (MHB) were obtained from Oxoid Ltd (Hampshire, UK). PBS and TSB were adjusted to pH 10 by addition of sodium hydroxide.

Proteus mirabilis ATCC 35508 and Staphylococcus aureus ATCC 6538 (LGC Standards, Middlesex, UK) were maintained on cryopreservative beads (Protect Bacterial Preservation System, Technical Service Consultants Ltd., UK) in 10\% glycerol at $-80^{\circ} \mathrm{C}$ and cultivated in $\mathrm{MHB}$ at $37^{\circ} \mathrm{C}$ when required for the microbiological assessments.<smiles>[R7]OC(=O)c1cn(CC)c2nc(C)ccc2c1=O</smiles>

$$
\text { 1: } R^{\prime}=\curvearrowright
$$<smiles></smiles><smiles>C=CCCCCCCCCC=[Ru]</smiles>

Figure 1: Molecular structures of polymerisable ester drug conjugates: 1-ethyl-7methyl-4-oxo-1,4-dihydro-1,8-naphthyridine-3-carboxylic acid 2-propen-1-ol ester 1; 1-ethyl-7-methyl-4-oxo-1,4-dihydro-1,8-naphthyridine-3-carboxylic acid 3-buten-1-ol ester 2; and 1-ethyl-7-methyl-4-oxo-1,4-dihydro-1,8-naphthyridine-3-carboxylic acid 9-decen-1-ol ester 3. 


\section{Methods}

Synthesis of Poly(2-Hydroxyethyl Methacrylate) (p(HEMA)) Homopolymers

Films of p(HEMA) were synthesised, as previously described, (13) by dissolving EGDMA (1\% w/w) and AIBN (1\% w/w) (crosslinker and initiator, respectively) at ambient temperature in 2-HEMA $(98 \% \mathrm{w} / \mathrm{w})$, with stirring. The total mass of polymer was $10 \mathrm{~g}$. The resulting solution was injected slowly into moulds comprising two glass plates, which were separated with medical grade silicone tubing with lumen diameter of $0.3 \mathrm{~mm}$ and wall thickness of $0.18 \mathrm{~mm}$, lined with release liner, and clamped using spring clips. Following polymerisation at $90^{\circ} \mathrm{C}$ for a period of $3 \mathrm{~h}$, the formed films were soaked for one week in deionised water to remove unreacted monomers and initiator, then dried to constant weight in an oven at $60^{\circ} \mathrm{C}$ to form xerogels. The removal of all monomers from the films was verified by monitoring acrylate absorption in the rinsing media at $220 \mathrm{~nm}$.

\section{Synthesis of Nalidixic Acid Conjugate-HEMA Copolymers}

Copolymers 4-6 were synthesised by stirring the respective conjugate from 1-3 (5\% w/w) with EGDMA (1\% w/w) and AIBN (1\% w/w) at ambient temperature with 2HEMA $(93 \% \mathrm{w} / \mathrm{w})$. The resulting solution was injected slowly into moulds, as described for p(HEMA), then polymerised at $90^{\circ} \mathrm{C}$ for one week. In all cases, total copolymer mass was $10 \mathrm{~g}$. The formed copolymers were soaked for three weeks in deionised water to remove unreacted monomers.

\section{Contact Angle Analysis}

Sessile contact angles of the surfaces of the p(HEMA) homopolymer and the drug conjugate-HEMA copolymers 4-6 were determined using a First Ten Ångströms (FTA) 200 video-based contact angle analyser (Portsmouth, Virginia, USA) in conjunction with FTA 32 video software for image capture and analysis. The tangent associated with a single drop of deionised water, used as the wetting medium, was measured in the equilibrium position on the sample surface. $(14,15)$

\section{Equilibrium Swelling Studies}

The equilibrium degrees of swelling of p(HEMA) and the drug conjugate-HEMA copolymers 4-6 were examined in $\mathrm{pH} 7$ universal buffer, prepared according to the formulation of Koller et al. (1992) (16) reported in Table 1 . Replicate discs $\left(1 \mathrm{~cm}^{2}\right)$ were dried in an oven at $60^{\circ} \mathrm{C}$ until constant weight, weighed, and placed in $\mathrm{pH} 7$ universal buffer. At designated intervals, discs were removed, blotted with filter paper to remove excess surface water, and reweighed, as previously described. (17) Discs were returned to the buffer media and soaked until no further change in mass. The weight percentage of buffer within the swollen polymer, designated as the equilibrium water content (EWC), was calculated according to the following equation (18) :

$$
\operatorname{EWC}(\%)=\left(M_{\mathrm{f}}-M_{\mathrm{i}}\right) / M_{\mathrm{i}} \times 100
$$

where $M_{\mathrm{f}}$ and $M_{\mathrm{i}}$ represent the final sample mass after water absorption and the initial dried sample mass respectively. 
Table 1: Formulation of Universal Buffer

\begin{tabular}{ccccc}
\hline $\mathrm{pH}$ & $\begin{array}{c}\text { Stock } \\
(\mu \mathrm{L})^{\mathrm{a}}\end{array}$ & $\begin{array}{c}2 \mathrm{M} \\
\mathrm{NaOH} \\
(\mu \mathrm{L})\end{array}$ & $\begin{array}{c}\mathrm{KCl} \\
(\mathrm{mg})\end{array}$ & $\begin{array}{c}\mathrm{H}_{2} \mathrm{O} \\
(\mathrm{mL})\end{array}$ \\
\hline 7 & 833 & 437 & 25.8 & 11.43 \\
10 & 714 & 557 & 0 & 11.44 \\
\hline
\end{tabular}

a Stock solution $(100 \mathrm{~mL})$ contained $2.7 \mathrm{~mL} \mathrm{H}_{3} \mathrm{PO}_{4}, 2.29 \mathrm{~mL} \mathrm{AcOH}$ and $2.48 \mathrm{~g} \mathrm{H}_{3} \mathrm{BO}_{3}$ dissolved in deionised $\mathrm{H}_{2} \mathrm{O}$. (16)

\section{In Vitro pH-Mediated Drug Release Kinetics}

Kinetics of nalidixic acid release from the drug conjugate-HEMA copolymers 4-6 were examined at $\mathrm{pH} 7$ and $\mathrm{pH} 10$ in universal buffer solutions with constant ionic strength, prepared according to the formulation of Koller et al. (1992) (16) reported in Table 1. Pre-swollen copolymer discs $\left(1 \mathrm{~cm}^{2}\right)$, suspended on a needle, were placed in McCartney bottles containing $10 \mathrm{~mL}$ pre-warmed universal buffer solution of the appropriate $\mathrm{pH}$ and shaken at $37^{\circ} \mathrm{C}$ in an oscillating water bath (100 rpm). At predetermined intervals, the discs were transferred to fresh media $(10 \mathrm{~mL}$, to ensure sink conditions) and the released drug quantified by UV-visible spectroscopy ( $\lambda=$ $257 \mathrm{~nm}$ ), with concentration dependence of nalidixic acid on absorbance determined from calibration curves prepared using universal buffer of the appropriate $\mathrm{pH}\left(\mathrm{r}^{2}>\right.$ 0.999), as previously described. (19) Release experiments at each $\mathrm{pH}$ were performed in quintuplicate.

\section{In Vitro Microbiological Analysis}

Bacterial suspensions of $P$. mirabilis and $S$. aureus $\left(1 \times 10^{8} \mathrm{cfumL}^{-1}\right)$, in either PBS (pH 7) supplemented with $0.5 \%$ TSB (pH 7), or PBS ( $\mathrm{pH} 10$ ) supplemented with 1\% TSB (pH 10), were diluted 1 in 100 with PBS containing $0.5 \%$ TSB of the required $\mathrm{pH}$. Replicate discs (8 mm) of copolymers 4-6 and p(HEMA) (as control) were cut from the polymer films, placed in individual wells of a 24-well flat bottom tissue culture plate (Corning Inc., Corning, NY), and completely immersed with aliquots of the bacterial suspension ( $1 \mathrm{~mL}$ ) with density of $1 \times 10^{6} \mathrm{cfumL}^{-1}$. The plates were continuously shaken in an orbital incubator at $37^{\circ} \mathrm{C}$. After designated time intervals of $4 \mathrm{~h}$ and $24 \mathrm{~h}$, the discs were removed from the bacterial suspension using sterile forceps, and non-adherent bacteria removed by washing for $30 \mathrm{sec}$ in QSRS (3 x 5 $\mathrm{mL})$. (20) The discs were transferred into fresh QSRS (5 mL), sonicated for $10 \mathrm{~min}$, and vortexed for $30 \mathrm{~s}$ to remove adherent bacteria. A viable count of the QSRS was performed by the Miles and Misra serial dilution technique, (21) followed by plating onto low-swarm (LSW) agar (P. mirabilis) or Mueller-Hinton agar (S. aureus) to enumerate the previously adhered bacteria per disc. The sonication technique has previously been demonstrated not to affect bacterial viability or morphology. (22)

\section{Statistical Analysis}

Statistical differences between the surface contact angles and equilibrium water contents of copolymers 4-6 and the p(HEMA) homopolymer were evaluated by a oneway analysis of variance, whereas the effect of $\mathrm{pH}$ and conjugate alkyl chain length on the cumulative amounts of nalidixic acid released at designated intervals, and the effect of $\mathrm{pH}$ and copolymerisation with the ester drug conjugates on bacterial adherence after $4 \mathrm{~h}$ and $24 \mathrm{~h}$ were statistically evaluated by a two-way analysis of 
variance, followed by Tukey's honestly significant difference test for post-hoc comparisons between means of individual groups. In all cases, differences were considered significant when $p<0.05$. (23)

\section{Results and Discussion}

The effect of copolymerisation with the drug conjugates on surface wettability and swelling characteristics was herein examined to assess changes in surface hydrophilicity/hydrophobicity and resulting water contents. These surface properties not only play a role in controlling rates of drug release, but are also involved in determining ultimate device performance in vivo. Application of the synthesised copolymers as medical device coatings provides a useful mechanism of modifying surface properties to optimise resistance to bacterial colonisation, improve device biocompatibility and minimise frictional irritation during device insertion and removal, whilst retaining bulk mechanical properties. $(10,11)$

\section{Contact Angle Analysis}

The water wettability of the nalidixic acid conjugate-HEMA copolymers 4-6, prepared from the respective conjugates 1-3 (5\% w/w), 2-HEMA (93\%), and EGDMA crosslinker (1\% w/w), was assessed in comparison to the control p(HEMA) homopolymer by measuring the static contact angles of deionised water on the sample surfaces. The contact angles measured for the materials are presented in Table 2.

Table 2: Static Contact Angles of p(HEMA) and Nalidixic Acid Conjugate-HEMA Copolymers

\begin{tabular}{|c|c|}
\hline Polymer & $\begin{array}{c}\text { Contact Angle }\left(^{\circ}\right) \\
(\text { Mean } \pm \text { S.D.) }\end{array}$ \\
\hline p(HEMA) & $52.5 \pm 3.86$ \\
\hline 4 & $75.6 \pm 3.44$ \\
\hline 5 & $80.1 \pm 3.25$ \\
\hline 6 & $61.5 \pm 2.63$ \\
\hline
\end{tabular}

Copolymerisation with the ester drug conjugates 1-3 (5\% w/w) caused a significant increase in surface contact angle relative to the p(HEMA) homopolymer, as reported in Table 2. This observed reduction in water wettability of the material surfaces was most likely attributed to the partial replacement of hydrophilic $\mathrm{OH}$ groups of p(HEMA) with comparatively more hydrophobic $\mathrm{CH}$ moieties of the conjugate alkyl chains.

In contrast to the expected effect of alkyl chain length on water wettability of the surface, (24) post-hoc analysis herein revealed that the surface of the longer-chain conjugate copolymer $\mathbf{6}$ was significantly more hydrophilic, as inferred by the statistically lower contact angle $\left(61.5^{\circ}\right)$, than the surfaces of the shorter-chain conjugate copolymers 4 and 5 ( $75.6^{\circ}$ and $80.1^{\circ}$, respectively). This observation was related to the higher relative molecular mass of conjugate 3 and the resultant lower molar ratio of amphiphilic nalidixic moieties within copolymer $\mathbf{6}$ than within copolymers synthesised from conjugates $\mathbf{1}$ or $\mathbf{2}$. Relative to p(HEMA), the surface of $\mathbf{6}$ was consequentially modified to a lower extent than the surfaces of the shorterchain conjugate copolymers $\mathbf{4}$ and $\mathbf{5}$. In accordance with previous reports, (25) differences in the surface orientation of the amphiphilic nalidixic moiety, namely 
closer proximity to the surfaces of the short-chain conjugate copolymers $\mathbf{4}$ and $\mathbf{5}$ than the surface of copolymer $\mathbf{6}$, as a result of outward projection of this functional group by the longer alkyl chains of the latter, furthermore, contributed to the greater reduction in surface hydrophilicity observed with copolymers $\mathbf{4}$ and $\mathbf{5}$.

\section{Equilibrium Swelling Studies}

The equilibrium water contents (EWCs) of the drug conjugate-HEMA copolymers 4, $\mathbf{5}$ and $\mathbf{6}$ in comparison to the p(HEMA) homopolymer, recorded after immersion in pH 7 universal buffer for 72 h, after which no further weight increase was recorded, are reported in Table 3.

Table 3: Equilibrium Water Contents of p(HEMA) and Nalidixic Acid ConjugateHEMA Copolymers

\begin{tabular}{cc}
\hline Polymer & $\begin{array}{c}\text { EWC } \\
(\%)( \pm \text { S.D. })\end{array}$ \\
\hline p(HEMA) & $75.6 \pm 0.76$ \\
$\mathbf{4}$ & $74.0 \pm 0.90$ \\
$\mathbf{5}$ & $75.1 \pm 1.07$ \\
$\mathbf{6}$ & $70.3 \pm 0.58$ \\
\hline
\end{tabular}

Copolymer 6, synthesised from 2-HEMA and the longer-chain conjugate 3, displayed a statistically lower EWC than the p(HEMA) homopolymer and short-chain conjugate copolymers $\mathbf{4}$ and $\mathbf{5}$ (Table 3). Polymer swelling is dependent on properties of the swelling medium, such as $\mathrm{pH}$, temperature and ionic strength, and the polymer itself, such as the hydrophilic/hydrophobic balance, crosslink density and the presence of ionisable functional groups. (26) In contrast to the constant universal buffer and degree of crosslinking $(1 \% \mathrm{w} / \mathrm{w})$, one factor that was comonomer-dependent and played a predominant role in the significant difference in EWC between p(HEMA) and copolymer $\mathbf{6}$ observed herein was the hydrophilic/hydrophobic balance of the polymer networks. As previously reported, (27) the more hydrophobic nature of the longer-chain conjugate $\mathbf{3}$ in comparison to 2-HEMA, $\mathbf{1}$ and $\mathbf{2}$ was responsible for reducing the overall polymer wettability and weakening the subsequent interactions between the copolymer network and the aqueous swelling medium. In addition, chain entanglements of the long alkyl chain of conjugate 3 within the copolymer effectively interrupted relaxation of the polymer network and thereby reduced the resultant degree of swelling.

\section{In Vitro pH-Mediated Nalidixic Acid Release Kinetics}

The theory behind the development of these three-dimensional chemically-conjugated drug delivery systems as candidate infection-resistant catheter coatings is that upon elevation of urinary $\mathrm{pH}$, hydrolysis of the ester bond linking nalidixic acid to the alkyl spacer moiety will be triggered with immediate effect, allowing free drug to effectively target biofilm bacteria at their fulcrum for adherence, before secretion of the protective glycocalyx. To investigate the $\mathrm{pH}$-responsive properties of these ester drug conjugate-HEMA copolymers, the rate of nalidixic acid release from copolymers 4-6 was characterised as a function of $\mathrm{pH}$. Furthermore, the concept of tailoring rates of release via the employment of spacers of varying vinyl chain lengths was explored. Indwelling catheters may remain in situ for up to six weeks between scheduled changes, therefore release studies were continued for $>42$ days to assess ester bond 
stability during typical periods of device implantation. The in vitro $\mathrm{pH}$-mediated kinetics of nalidixic acid release from copolymers 4-6 are displayed in Figure 2.

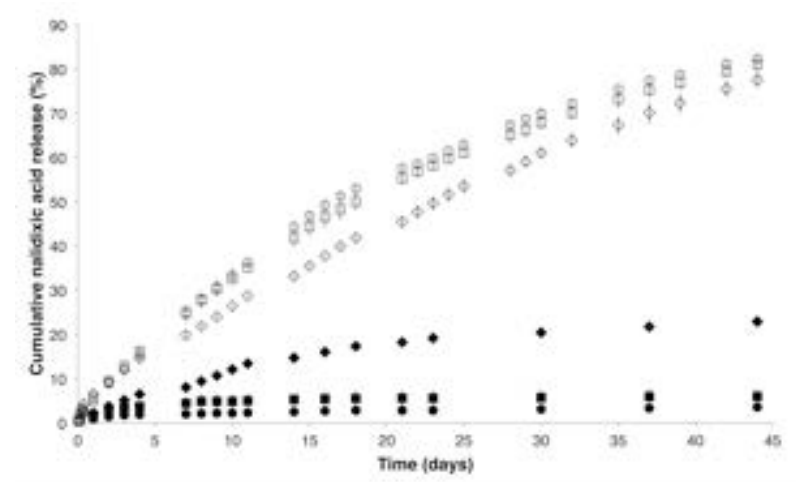

Figure 2: The effect of $\mathrm{pH}$ on the mean ( \pm S.D.) release of nalidixic acid from copolymers 4, 5 and 6, represented by circles, squares and diamonds, respectively, at $37^{\circ} \mathrm{C}$ with shaking. Sink conditions were maintained throughout the study. Open and closed symbols refer to release at $\mathrm{pH} 10$ and $\mathrm{pH} 7$ respectively.

All copolymers displayed the same general trend in terms of release rate with respect to $\mathrm{pH}$ of the dissolution media. The ester bond mediating attachment of nalidixic acid to the alkyl spacer moiety was relatively stable at normal physiological urine $\mathrm{pH}, \mathrm{pH}$ $7,(28,29)$ and therefore successfully delayed drug release from the copolymers, in contrast to the significantly more rapid rates of release demonstrated at the elevated $\mathrm{pH}$ typical of CAUTIs, $\mathrm{pH}$ 10, as shown in Figure 2. This strategy is therefore of major applicability towards the development of infection-responsive urinary catheter coatings. As a representative example, cumulative release of nalidixic acid after one week from copolymer 4 was 12-fold greater at $\mathrm{pH} 10$ than at $\mathrm{pH}$ 7; cumulative amounts of nalidixic acid released were $24.6 \%$ and $1.99 \%$, respectively. We have previously reported the rapid diffusion-controlled release of nalidixic acid from physically-loaded p(HEMA) matrices, where more than $90 \%$ of the loaded nalidixic acid was released from the hydrogels within one hour of immersion in media of $\mathrm{pH} 7$ and $\mathrm{pH}$ 9. (13) Release of nalidixic acid from the synthesised copolymers described herein, in contrast, approximated $80 \%$ after six weeks in media of $\mathrm{pH} 10$, confirming the mechanism of release as hydrolysis-controlled. The increase in release kinetics as the concentration of hydroxide ions increased was attributed to basic catalysis of the hydrolysis reaction, as previously reported. (30)

In addition to environmental conditions, hydrolysis of polymer-drug conjugates is dependent on factors such as the nature and stability of the hydrolysable bond, the physical and chemical composition of the polymer, and steric overcrowding at the cleavage site, (31) however, conflicting reports regarding the relative importance of these factors are found. $(32,33)$ Of particular relevance to this in vitro study is the previously reported faster liberation of acyclovir, via ester hydrolysis, from polymer prodrugs with longer spacer moieties between the drug and the main polymer chain, attributed to the reduced steric hindrance for the incoming hydrolytic species. (34) The effect of conjugate alkyl chain length on subsequent release kinetics in this study was, however, less evident, particularly in buffer of $\mathrm{pH} 10$. In contrast to the expected faster hydrolysis and subsequent release of nalidixic acid from the longer-chain conjugate copolymer $\mathbf{6}$ than from the shorter-chain conjugate copolymers $\mathbf{4}$ and $\mathbf{5}$, as was observed at $\mathrm{pH} 7$ (cumulative release from copolymers $\mathbf{4}$, 5 and 6 approximated 1.99\%, 4.42\% and 8.02\% respectively after one week), 
cumulative amounts of nalidixic acid released from $\mathbf{6}$ were lower than from $\mathbf{4}$ and $\mathbf{5}$ from day three onwards at $\mathrm{pH} 10$, following release of the surface-localised nalidixic acid. For example, after one week, cumulative release approximated 25.1\%, 24.6\% and $\mathbf{1 9 . 8 \%}$ from copolymers $\mathbf{4 , 5}$ and $\mathbf{6}$, respectively. Reduced significance of ester bond accessibility to rates of drug release in media of alkaline $\mathrm{pH}$ has previously been attributed to the higher ester reactivity at elevated $\mathrm{pH}$. (30) Furthermore, the comparatively lower rates of nalidixic acid release from copolymer $\mathbf{6}$ than from the shorter-chain conjugate copolymers $\mathbf{4}$ and $\mathbf{5}$ at pH 10 was a combined result of the more tortuous copolymer matrix and the associated increase in hydrophobicity within the vicinity of the ester bond upon employment of longer alkyl spacers, as has been previously reported. $(10,27)$

Importantly, to effectively prevent bacterial colonisation, concentrations of drug in the release phase must exceed those required for inhibitory and cidal effects against the respective pathogens. This was assessed by in vitro microbiological studies and is reported below.

\section{In Vitro Microbiological Analysis}

To establish the utility of these chemically-triggered drug delivery matrices as biofilm-resistant urinary catheter coatings, the efficacy of the copolymers in resisting adherence of $P$. mirabilis and $S$. aureus relative to the p(HEMA) homopolymer was assessed herein by challenging samples of 4, 5, 6 and p(HEMA) with inoculi of $1 \mathrm{x}$ $10^{6}$ cfumL $^{-1}$ in media of $\mathrm{pH} 7$ and $\mathrm{pH} 10$ over time periods of $4 \mathrm{~h}$ and $24 \mathrm{~h}$.

Adherence of $P$. mirabilis to the drug conjugate-HEMA copolymers relative to the control p(HEMA) homopolymer is displayed in Figure 3.

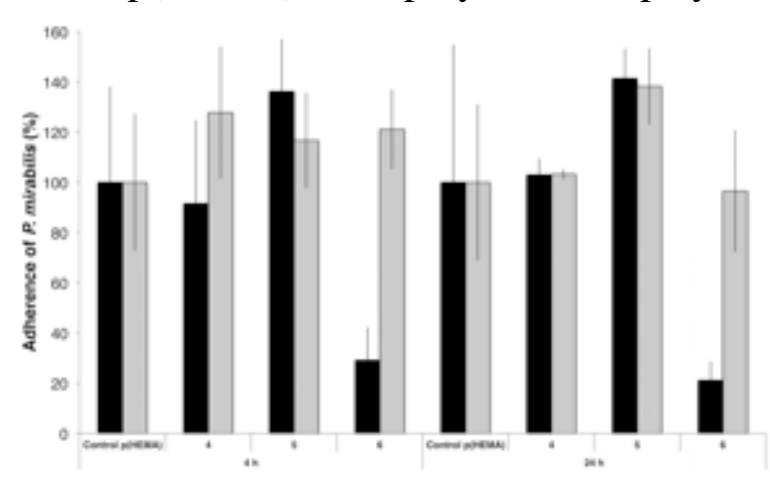

Figure 3: Microbial adherence (\%) of $P$. mirabilis to unmodified p(HEMA) and copolymers of 2-HEMA and conjugates 1, 2 and 3, relative to the p(HEMA) homopolymer, denoted control, after $4 \mathrm{~h}$ and $24 \mathrm{~h}$ incubation at $37^{\circ} \mathrm{C}$ in media of $\mathrm{pH}$ 7 (black) and pH 10 (grey). Columns and error bars represent means \pm S.E. $(n=5)$.

The greatest reductions in bacterial adherence relative to the p(HEMA) control were achieved by copolymer 6 in media of $\mathrm{pH} 7$, with adherence reduced by mean values of $70.9 \%$ and $78.9 \%$ after $4 \mathrm{~h}$ and $24 \mathrm{~h}$, respectively (Figure 3). Critical concentrations of nalidixic acid required for inhibitory and cidal effects against $P$. mirabilis have previously been determined as $9.38 \mathrm{mgL}^{-1}$ and $37.50 \mathrm{mgL}^{-1}$ (pH 7), and $26.04 \mathrm{mgL}^{-1}$ and $83.33 \mathrm{mgL}^{-1}$ (pH 10), respectively. Consequential to the low initial loading of the drug conjugate monomers, the mean concentrations of nalidixic acid released from discs $\left(1 \mathrm{~cm}^{2}\right)$ of $\mathbf{4 , 5}$ and $\mathbf{6}$ in $\mathrm{pH} 7$ buffer after $24 \mathrm{~h}$ were 0.29 $\mathrm{mgL}^{-1}, 0.50 \mathrm{mgL}^{-1}$ and $2.23 \mathrm{mgL}^{-1}$, respectively. Furthermore, in $\mathrm{pH} 10$ buffer, when release was most rapid, cumulative release was again too low: mean concentrations of nalidixic acid were $1.59 \mathrm{mgL}^{-1}, 1.59 \mathrm{mgL}^{-1}$ and $6.75 \mathrm{mgL}^{-1}$ after $24 \mathrm{~h}$ incubation of 
discs $\left(1 \mathrm{~cm}^{2}\right)$ of $\mathbf{4 , 5}$ and $\mathbf{6}$, respectively. In vivo, however, concentrations are dependent on the site of implantation; in contrast to the relatively high urinary turnover rates experienced by ureteral stents as a result of the constant flow of urine from the kidneys, Foley catheters are subjected to comparatively lower turnover rates. Moreover, the retention balloon and the section of catheter immediately above the balloon reside within the bladder and are consequentially exposed to an essentially stagnant pool of urine. (35)

The differences in bacterial adherence observed, for example, between copolymer 6 and the p(HEMA) control were therefore caused by changes in the physicochemical properties of the material surface, namely the reduction in surface wettability after copolymerisation with conjugate $\mathbf{3}$ in combination with the outward projection of the alkyl chains of $\mathbf{3}$ away from the copolymer surface, which ultimately make the surface less attractive to bacterial attachment.

The comparative resistances of the nalidixic acid conjugate-HEMA copolymer and p(HEMA) homopolymer surfaces to adherence of S. aureus at pH 7 and pH 10 are displayed in Figure 4.

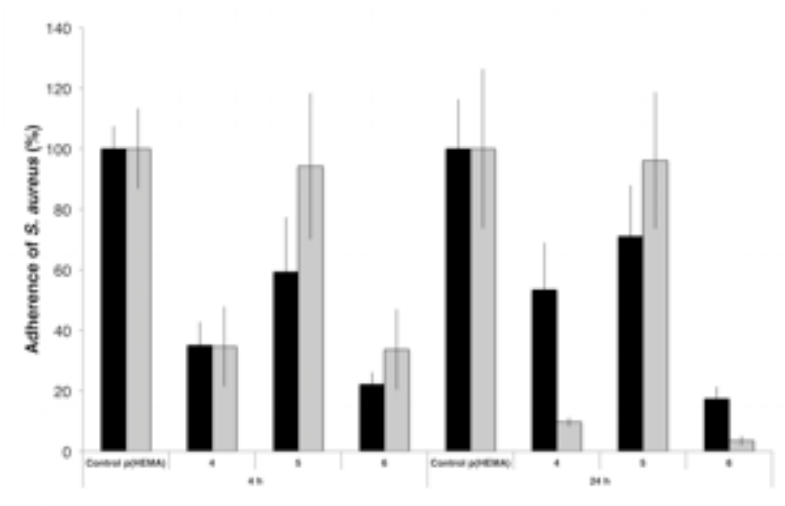

Figure 4: Microbial adherence (\%) of S. aureus after $4 \mathrm{~h}$ and $24 \mathrm{~h}$ to unmodified p(HEMA) and copolymers of 2-HEMA and conjugates $\mathbf{1}, 2$ and 3, relative to the p(HEMA) homopolymer, denoted control, after $4 \mathrm{~h}$ and $24 \mathrm{~h}$ incubation at $37^{\circ} \mathrm{C}$ in media of pH 7 (black) and pH 10 (grey). Columns and error bars represent means \pm S.E. $(n=5)$.

After $4 \mathrm{~h}$ contact with the $S$. aureus challenge, significant reductions in bacterial adherence to copolymer $\mathbf{6}$ relative to the p(HEMA) homopolymer were demonstrated, irrespective of $\mathrm{pH}$, with adherence reduced by mean values of $77.8 \%$ and $66.3 \%$ at $\mathrm{pH}$ 7 and $\mathrm{pH} 10$, respectively. These significant reductions in bacterial adherence to copolymer 6 relative to the p(HEMA) homopolymer were maintained after $24 \mathrm{~h}$ contact with the bacterial challenge. Bacterial adherence to copolymer 4 after $24 \mathrm{~h}$ in pH 10 media was also significantly reduced relative to the p(HEMA) homopolymers suspended in $\mathrm{pH} 7$ and $\mathrm{pH} 10$ media.

Again these differences in bacterial adherence to the copolymers relative to the p(HEMA) control were attributed to factors other than the bacteriostatic or bactericidal activities of nalidixic acid due to the low amounts of nalidixic acid released from the copolymers and the well-established poor activity of this quinolone antibacterial agent against Staphylococci spp.. MIC values of nalidixic acid against $S$. aureus have previously been determined as $23 \mathrm{mgL}^{-1}$ and $1000 \mathrm{mgL}^{-1}$ at $\mathrm{pH} 7$ and $\mathrm{pH}$ 10 , respectively, whereas no cidal activity was demonstrated against this isolate at either $\mathrm{pH}$ value when concentrations up to $2000 \mathrm{mgL}^{-1}$ were tested. The observed 
reductions in bacterial adherence were therefore again attributed to changes in surface wettability and the presence of surface-localised alkyl chains following copolymerisation with the respective drug conjugates.

Despite a low initial conjugate loading of $5 \% \mathrm{w} / \mathrm{w}$ within the copolymer, an encouraging, greater than one-logarithmic reduction in adherence of $S$. aureus was achieved by copolymer 6 relative to the p(HEMA) control after $24 \mathrm{~h}$ in pH 10 media. Tuning of the drug conjugate loading within the copolymers to promote greater release of nalidixic acid from the surface is therefore expected to ultimately enhance the efficacy of the synthesised copolymers in resisting bacterial adherence relative to unmodified $\mathrm{p}(\mathrm{HEMA})$.

\section{Conclusions}

The smart polymeric prodrug matrices developed herein as candidate infectionresponsive drug delivery systems are capable of releasing antimicrobial agents specifically, and rapidly, upon elevation of $\mathrm{pH}$ to values typically reported at the onset of urinary catheter infections. All nalidixic acid conjugate-HEMA copolymers clearly demonstrate triggered release profiles with negligible release at $\mathrm{pH} 7$, in the absence of urease-producing pathogens, and up to 20-fold faster rates of release upon elevation of $\mathrm{pH}$ to $\mathrm{pH} 10$, as occurs in vivo due to the urease-catalysed hydrolysis of urea to ammonia. Initial microbiological assessment of copolymers containing a 5\% w/w loading of drug conjugate suggests that application of the conjugate-HEMA copolymers as urinary catheter coatings is a promising strategy towards the prevention of CAUTIs in vivo.

\section{Acknowledgements}

This work was funded by the Department for Employment and Learning, Northern Ireland. The use of the EPSRC National Mass Spectrometry Service Centre, Swansea, is gratefully acknowledged.

\section{References}

1. Lendlein, A.; Pierce, B.F.; Ambrosio, L.; Grijpma, D.W. Advanced functional polymers for medicine. Macromolecular Bioscience 2011, 11, 1621-1624.

2. Nicolle, L.E. Catheter-acquired urinary tract infection: The once and future guidelines. Infection Control and Hospital Epidemiology 2010, 31, 327-329.

3. Stickler, D.J. and Morgan, S.D. Modulation of crystalline Proteus mirabilis biofilm development on urinary catheters. J. Med. Microbiol. 2006, 55, 489-494.

4. Stickler, D.J. and Feneley, R.C. The encrustation and blockage of long-term indwelling bladder catheters: a way forward in prevention and control. Spinal Cord 2010, 48, 784-790.

5. Gultekinoglu, M.; Sarisozen, Y.T.; Erdogdu, C.; Sagiroglu, M.; Aksoy, E.A.; Oh, Y.J.; Hinterdorfer, P.; Ulubayram, K. Designing of dynamic polyethyleneimine (PEI) 
brushes on polyurethane (PU) ureteral stents to prevent infections. Acta Biomaterialia 2015, 21, 44-54.

6. Wei, Q.; Becherer, T.; Noeske, P.M.; Grunwald, I.; Haag, R. A universal approach to crosslinked hierarchical polymer multilayers as stable and highly effective antifouling coatings. Adv Mater 2014, 26, 2688-2693.

7. Campoccia, D.; Montanaro, L.; Speziale, P.; Arciola, C. Antibiotic-loaded biomaterials and the risks for the spread of antibiotic resistance following their prophylactic and therapeutic clinical use. Biomaterials 2010, 31, 6363-6377.

8. McCoy, C.P.; Brady, C.; Cowley, J.; McGlinchey, S.; McGoldrick, N.; Kinnear, D. Triggered drug delivery from biomaterials. Expert Opinion on Drug Delivery 2010, 7, 605-616.

9. Huynh, T.; Padois, K.; Sonvico, F.; Rossi, A.; Zani, F.; Pirot, F. Characterization of a polyurethane-based controlled release system for local delivery of chlorhexidine diacetate. European Journal of Pharmaceutics and Biopharmaceutics 2010, 74, 255264.

10. Schoenmakers, R.; van de Wetering, P.; Elbert, D.; Hubbell, J. The effect of the linker on the hydrolysis rate of drug-linked ester bonds. J. Controlled Release 2004, 95, 291-300.

11. Nowatzki, P.J.; Koepsel, R.R.; Stoodley, P.; Min, K.; Harper, A.; Murata, H.; Donfack, J.; Hortelano, E.R.; Ehrlich, G.D.; Russell, A.J. Salicylic acid-releasing polyurethane acrylate polymers as anti-biofilm urological catheter coatings. Acta Biomaterialia 2012, 8, 1869-1880.

12. McCoy, C.P.; Irwin, N.J.; Brady, C.; Jones, D.S.; Andrews, G.P.; Gorman, S.P. Synthesis and release kinetics of polymerisable ester drug conjugates: towards $\mathrm{pH}-$ responsive infection-resistant urinary biomaterials. Tetrahedron Lett. 2013, 54, 25112514.

13. Irwin, N.J.; McCoy, C.P.; Jones, D.S.; Gorman, S.P. Infection-responsive drug delivery from urinary biomaterials controlled by a novel kinetic and thermodynamic approach. Pharm. Res. 2013, 30, 857-865.

14. McCoy, C.P.; Cowley, J.F.; Gorman, S.P.; Andrews, G.P.; Jones, D.S. Reduction of Staphylococcus aureus and Pseudomonas aeruginosa colonisation on PVC through covalent surface attachment of fluorinated thiols. J. Pharm. Pharmacol. 2009, 61, 1163-1169.

15. Merrett, K.; Cornelius, R.M.; McClung, W.G.; Unsworth, L.D.; Sheardown, H. Surface analysis methods for characterizing polymeric biomaterials. Journal of Biomaterials Science-Polymer Edition 2002, 13, 593-621.

16. Koller, C.N.; Bauer, L.S.; Hollingworth, R.M. Characterization of the $\mathrm{pH}-$ mediated solubility of Bacillus thuringiensis var. san diego native [delta]-endotoxin crystals. Biochem. Biophys. Res. Commun. 1992, 184, 692-699. 
17. Jones, D.S.; Andrews, G.P.; Caldwell, D.L.; Lorimer, C.; Gorman, S.P.; McCoy, C.P. Novel semi-interpenetrating hydrogel networks with enhanced mechanical properties and thermoresponsive engineered drug delivery, designed as bioactive endotracheal tube biomaterials. European Journal of Pharmaceutics and Biopharmaceutics 2012, 82, 563-571.

18. Zahedi, P. and Lee, P.I. Solid molecular dispersions of poorly water-soluble drugs in poly(2-hydroxyethyl methacrylate) hydrogels. European Journal of Pharmaceutics and Biopharmaceutics 2007, 65, 320-328.

19. McCoy, C.P.; Morrow, R.; Edwards, C.; Jones, D.S.; Gorman, S.P. Neighboring group-controlled hydrolysis: towards "designer" drug release biomaterials. Bioconjug. Chem. 2007, 18, 209-215.

20. Wang, R.; Neoh, K.G.; Shi, Z.; Kang, E.; Tambyah, P.A.; Chiong, E. Inhibition of Escherichia coli and Proteus mirabilis adhesion and biofilm formation on medical grade silicone surface. Biotechnol. Bioeng. 2012, 109, 336-345.

21. Miles, A.A.; Misra, S.S.; Irwin, J.O. The estimation of the bactericidal power of the blood. J. Hyg. 1938, 38, 732-749.

22. Jones, D.S.; McGovern, J.G.; Woolfson, A.D.; Gorman, S.P. Role of physiological conditions in the oropharynx on the adherence of respiratory bacterial isolates to endotracheal tube poly(vinyl chloride). Biomaterials 1997, 18, 503-510.

23. Jones, D.S. Pharmaceutical Statistics. Pharmaceutical Press: London, 2002;

24. Ayala, R.; Zhang, C.; Yang, D.; Hwang, Y.; Aung, A.; Shroff, S.S.; Arce, F.T.; Lal, R.; Arya, G.; Varghese, S. Engineering the cell-material interface for controlling stem cell adhesion, migration, and differentiation. Biomaterials 2011, 32, 3700-3711.

25. Van Damme, H.S.; Hogt, A.H.; Feijen, J. Surface mobility and structural transitions of poly(n-alkyl methacrylates) probed by dynamic contact angle measurements. J. Colloid Interface Sci. 1986, 114, 167-172.

26. Siegel, R.A. and Rathbone, M.J. Overview of controlled release mechanisms, In Fundamentals and Applications of Controlled Release Drug Delivery, 1st ed.; Siepmann, R.A., Siegel, R.A. and Rathbone, M.J., Eds.; Springer: New York, USA, 2012; pp. 19-43.

27. Azema, J.; Guidetti, B.; Malet-Martino, M.; Martino, R.; Roques, C. Efficient approach to acyloxymethyl esters of nalidixic acid and in vitro evaluation as intraocular prodrugs. Bioorg. Med. Chem. 2006, 14, 2569-2580.

28. Lauridsen, M.; Hansen, S.H.; Jaroszewski, J.W.; Cornett, C. Human urine as test material in H-1 NMR-based metabonomics: Recommendations for sample preparation and storage. Anal. Chem. 2007, 79, 1181-1186. 
29. Osberg, I.; Chase, H.P.; Garg, S.K.; Deandrea, A.; Harris, S.; Hamilton, R.; Marshall, G. Effects of storage time and temperature on measurement of small concentrations of albumin in urine. Clin. Chem. 1990, 36, 1428-1430.

30. Gallardo, A.; Parejo, C.; San Roman, J. NSAIDs bound to methacrylic carriers: microstructural characterization and in vitro release analysis. J. Controlled Release 2001, 71, 127-140.

31. Mahkam, M. and Poorgholy, N. Novel pH-sensitive carriers containing naproxen pendant groups for colon-specific drug delivery. Int. J. Polym. Mater. 2010, 60, 1-10.

32. Etrych, T.; Kovai, L.; Strohalm, J.; Chytil, P.; Rihova, B.; Ulbrich, K.

Biodegradable star HPMA polymer-drug conjugates: Biodegradability, distribution and anti-tumor efficacy. J. Controlled Release 2011, 154, 241-248.

33. Griffith, L.G. Polymeric biomaterials. Acta Materialia 2000, 48, 263-277.

34. Li, X.; Lu, M.; Wu, Q.; Lv, D.; Lin, X. Novel designed polymer-acyclovir conjugates with linker-controlled drug release and hepatoma cell targeting. Journal of Polymer Science Part A: Polymer Chemistry 2008, 46, 117-126.

35. Gilmore, B.; Hamill, T.; Jones, D.; Gorman, S. Validation of the CDC biofilm reactor as a dynamic model for assessment of encrustation formation on urological device materials. Journal of Biomedical Materials Research Part B: Applied Biomaterials 2010, 93, 128-140. 